\title{
An FMEA analysis using grey theory and grey rough sets
}

\author{
Farshad Faezy Razi ${ }^{a^{*}}$, Abolfazl Danaei, Amir Ehsani and Changiz Dolati
}

Department of Management, Semnan Branch, Islamic Azad University, Semnan, Iran

\section{H R O N I C L E \\ A B S T R A C T}

Article history:

Received February 16, 2013

Received in revised format

6 May 2013

Accepted May 72013

Available online

May 82013

Keywords:

FMEA

$R P N$

Rough Set

Grey Theory

Grey Rough Sets

\begin{abstract}
This paper presents a hybrid method for detecting the most important failure items as well as the most effective alternative strategy to cope with possible events. The proposed model of this paper uses grey technique to rank various alternatives and FMEA technique to find important faults. The implementation of the proposed method has been illustrated for an existing example on the literature. The results of this method show that the proposed model has been capable of detecting the most trouble making problems with fuzzy logic and finds the most important solution strategy using FMEA technique.
\end{abstract}

\section{Introduction}

Traditional failure mode and effects analysis (FMEA) determines the risk priority number by detecting the multiplication of factor scores converted from the probability or degree of problem occurrence without considering the relative importance of factors. Supplier performance management and continuous improvement play essential role for organizational and supply chain development. There are several empirical studies, which provide insights into the relationships of supplier development practices to supplier performance. Bai and Sarkis (2011) introduced a multi-method technique relying on grey system theory and rough set theory, which could help organizations detect the important practices and programs associated with suppliers' performance. Bowles and Peláez (1995) described a new technique, based on fuzzy logic, for prioritizing failures for corrective actions in a Failure Mode, Effects and Criticality Analysis (FMECA) (Scipioni, \& Andreazza, 1997). Wang et al. (1995) presented a new design for safety of engineering systems with multiple failure state variables.

*Corresponding author.

E-mail addresses: farshadfaezy@yahoo.com (F. Faezy Razi)

(C) 2013 Growing Science Ltd. All rights reserved.

doi: $10.5267 /$ j.dsl.2013.05.001 
Chang et al. (1999) used fuzzy theory to remove the conversion debate by directly assessing the linguistic assessment of factors, and implemented grey theory to calculate risk priority number by assigning relative weighting coefficient without any utility function. They reported that concurrent use of fuzzy technique and grey theory could solve the problems arising from conventional FMEA, and could efficiently detect the potential failure modes and effects.

Bevilacqua et al. (2000) presented a new tool for FMEA method for a new Integrated Gasification and Combined Cycle plant in an important Italian oil refinery. The methodology was based on the integration between a modified FMECA and a Monte Carlo simulation as a technique for testing the weights assigned to the measure of the risk priority numbers (RPNs). The proposed RPN incorporated weighted sum of six parameters including safety, machine importance for the process, maintenance costs, failure frequency, downtime length, and operating conditions multiplied by an additional factor, the machine access difficulty.

Braglia (2000) developed a new tool for reliability and failure mode analysis by integrating the conventional aspects of the popular FMECA procedure with economic considerations where it integrates four various factors including chance of failure, chance of non-detection, severity, and expected cost. The applied the method in an actual application in an Italian refrigerator manufacturing company.

Sankar and Prabhu (2001) presented a new method for prioritizing failures for corrective actions in FMEA where the technique extended the risk prioritization beyond the conventional risk priority number (RPN) method. Rhee and Ishii (2003) implemented cost based FMEA to enhance reliability and serviceability. Braglia et al. (2003) presented an alternative FMECA multi-attribute decisionmaking approach where the technique was specifically intended to overcome some of the limitations concerning the use of the conventional US MIL-STD-1629A method. The approach was based on a fuzzy version of the 'technique for order preference by similarity to ideal solution' (TOPSIS) (Hwang \& Yoon, 1981). They used an application of an important Italian domestic appliance manufacturer and a comparison with conventional FMECA are reported to demonstrate the characteristics of the proposed method.

Wang et al. (2009) presented risk evaluation in failure mode and effects analysis using fuzzy weighted geometric mean. Yang et al. (2010) described a new fuzzy FMEA model integrating with fuzzy linguistic scale method. The model proposed a risk-space diagram to explicit the relationship of $\mathrm{S}, \mathrm{O}$ and $\mathrm{D}$. They compared the risk ranking of FMEA model with the criticality ranking about another similar type of $\mathrm{CNC}$ lathe and the results indicated that the method was basically the same with the actual situation.

Li et al. (2008) proposed a grey-based rough set technique to consider the supplier selection in supply chain management. They used grey system theory while at the same time utilizing data mining and knowledge discovery power of rough set theory. Hawkins and Woollons (1998) presented a method for risk analysis and demonstrated a manufactured aerospace component called a fuel-metering unit controlled by a negative feedback control scheme. Puente et al. (2002) described an alternative solution of applying FMEA to a wide variety of problems. The methodology was based on a decision system supported by qualitative rules, which provided a ranking of the risks of potential causes of production system failures.

In this paper, we present an empirical investigation to study to find important factors influencing working condition of a system. The proposed model of this paper uses grey technique to rank various alternatives and FMEA technique to find important faults. The organization of the paper first presents details of the proposed study in section 2, while section 3 presents details of the implementation of the proposed method for a real-world case study and concluding remarks are given in the last to summarize the contribution of the paper. 


\section{The proposed model: An FMEA method with Rough Set and Grey Theory}

The proposed model of this paper uses FMEA method with an adaptation of rough set and grey theory to determine the best solution strategy for the most critical failure in a CNC machine. In this method, we first prioritize alternative using grey theory and then we choose FMEA to find the most critical factors. This method is more applicable in group decision making techniques since more groups of people have better capabilities to detect failures. If we plan to find the most important failure case, we consider the following objective function,

$T=\left(U, A, V, f_{\otimes}\right)$,

where $U=\left\{S_{1}, S_{2}, \ldots, S_{M}\right\}$ is a set of alternative remedies or solution strategies, $A=\left\{a_{1}, a_{2}, \ldots, a_{n}\right\}$ is a set of failure attributes in RPN mode and $f \otimes: U \times A \rightarrow V$ is a grey function. All decisions are made based on $T=(U, A U D, f \otimes)$, where $D$ represents recognized solution strategies and $\otimes \mathrm{V}$ are defined based on FMEA method. The FMEA method consists of the following five steps,

1. Setup grey table based on FMEA method as follows,

$$
v_{i j}=\frac{1}{k}\left[\otimes v_{i j}^{1}+\otimes v_{i j}^{2}+\cdots+\otimes v_{i j}^{k}\right] \otimes
$$

where the value for each alternative $i$ for criterion $j$ is defined as follows,

$$
\otimes v_{i j}^{k}\left[\underline{v}_{i j}^{k}, \bar{v}_{i j}^{k}\right],(i=1,2, \ldots, m ; j=1,2, \ldots, n)
$$

2. Use Eq. (4) and Eq. (5) to normalize positive and negative criteria, respectively,

$$
\begin{aligned}
& \otimes v_{i j}^{*}=\left[\frac{\underline{v}_{i j}}{v_{j}^{\text {max }}}, \frac{\bar{v}_{i j}}{v_{j}^{\text {max }}}\right] \\
& \otimes v_{i j}^{*}=\left[\frac{v_{j}^{\text {min }}}{\bar{v}_{i j}}, \frac{v_{j}^{\text {min }}}{\underline{v}_{i j}}\right]
\end{aligned}
$$

3. Choose the best alternatives using the following method

\begin{tabular}{|c|c|c|c|c|c|}
\hline \multirow[t]{2}{*}{ Alternative } & \multicolumn{4}{|c|}{ Alternatives } & \multirow{2}{*}{$\begin{array}{c}\text { Decision } \\
\text { D }\end{array}$} \\
\hline & $\mathrm{a}_{1} *$ & $a_{2} *$ & ......... & $a_{n}^{*}$ & \\
\hline $\mathrm{S}_{1}$ & $\otimes v_{11}^{*}$ & $\otimes v_{12}^{*}$ & ........... & $\otimes v_{1 n}^{*}$ & $\mathrm{~d}_{1}$ \\
\hline $\mathrm{S}_{2}$ & $\otimes v_{21}^{*}$ & $\otimes v_{22}^{*}$ & $\ldots \ldots \ldots$ & $\otimes v_{2 n}^{*}$ & $\mathrm{~d}_{2}$ \\
\hline$\because:$ & : & : & : & : & $\ldots \ldots$. \\
\hline $\mathrm{S}_{\mathrm{m}}$ & $\otimes v_{m 1}^{*}$ & $\otimes v_{m 2}^{*}$ & ......... & $\otimes v_{m n}^{*}$ & $\mathrm{~d}_{\mathrm{m}}$ \\
\hline
\end{tabular}

$$
\begin{aligned}
& \mathrm{RS} *=\left\{\mathrm{S}_{\mathrm{i}} \in \mathrm{U} \mid\left[\mathrm{S}_{\mathrm{i}}\right]_{\mathrm{R}} \subseteq \mathrm{S} *\right\} \\
& \mathrm{S} *=\left\{\mathrm{S}_{\mathrm{i}} \mid \mathrm{d}_{\mathrm{i}}=\text { yes }\right\}
\end{aligned}
$$

4. Using Eq. (6) and Eq. (7) find the best possible choices as follows,

$\mathrm{S}^{\max }=\left\{\left[\max \underline{v}_{i 1}^{*}, \max \underline{v}_{i 1}^{*}\right], \ldots,\left[\max \underline{v_{i m}^{*}}, \max \underline{v}_{i m}^{*}\right]\right\}$

5. Use grey technique given by Bowles and Peláez (1995) as well as the information of Step 4 and recommend the best strategy.

\section{Solution strategy}

The proposed study of this paper uses a standard problem from the literature related to a CNC machinery problem. Table 1 demonstrates details of different possible failures. Fig. 1 also demonstrates details of the proposed model of this paper. 
Table 1

Details of various possible failures

\begin{tabular}{lll}
\hline Sub system & Item & Failure description \\
\hline \multirow{2}{*}{ Axis } & F1 & Get out a piece from the cylinder \\
& F2 & Unusual noise \\
& F3 & Full stop action in the axis of rotation \\
Toolbox & F4 & Shake the axis \\
& F5 & No interruption after work starts \\
\hline \multirow{2}{*}{ CNC system } & F6 & Interruption in operation \\
& F7 & Power failure \\
\hline \multirow{2}{*}{ Feeding system } & F8 & Without regard to the work \\
& F9 & After turning on the display does not work \\
\hline \multirow{2}{*}{ The electrical system } & F10 & Failure Monitor \\
\hline \multirow{2}{*}{ Hydraulic system } & F11 & Dielectric breakdown in the supply system \\
\hline System chip away & F12 & Departure from normal control feeding system \\
Lubrication system & F13 & Unusual noise \\
\hline
\end{tabular}

Fig. 1 shows details of the proposed model of this paper.

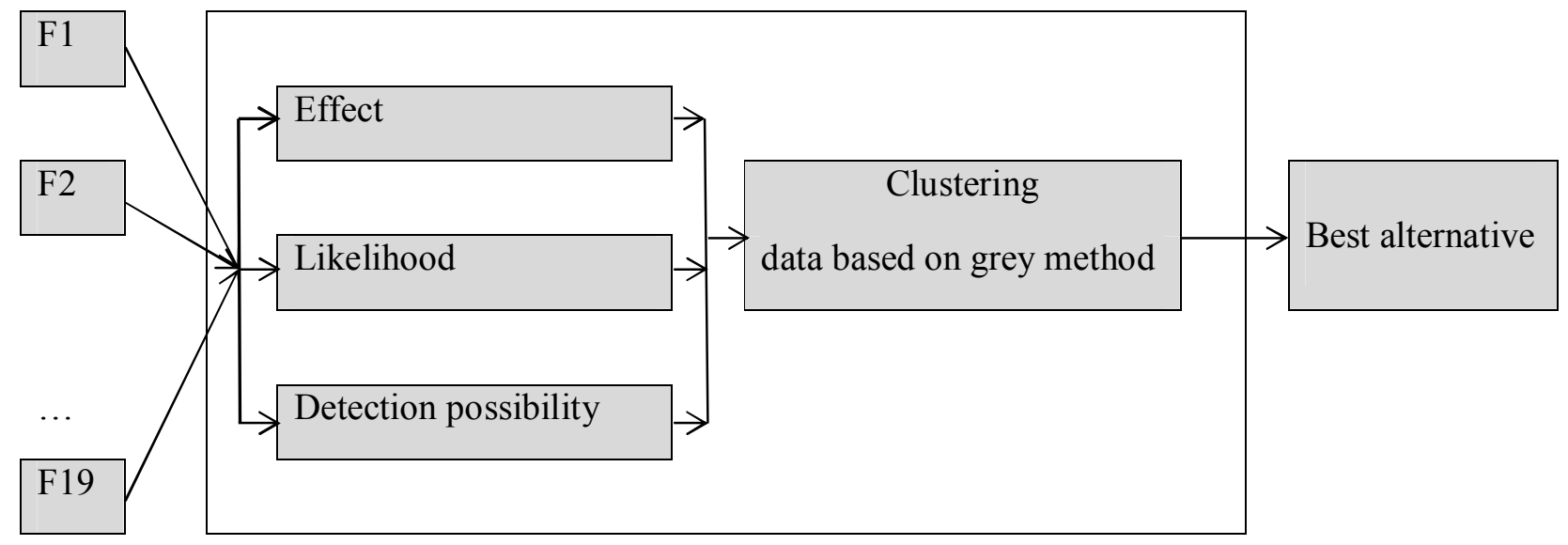

Fig. 1. The framework of the proposed study

To execute the proposed study of this paper, we first present table verbal preferences in Table 2 as follows,

\section{Table 2}

The summary of verbal preferences

\begin{tabular}{lccccc}
\hline Scale & Very much $(\mathrm{VH})$ & High $(\mathrm{H})$ & Medium $(\mathrm{M})$ & Low(L) & Very low (VL) \\
\hline $\mathrm{v}_{\mathrm{ij}}$ & {$\left[\begin{array}{ll}8 & 10\end{array}\right]$} & {$\left[\begin{array}{ll}6 & 9\end{array}\right]$} & {$\left[\begin{array}{ll}3 & 7\end{array}\right]$} & {$\left[\begin{array}{ll}1 & 4\end{array}\right]$} & $(\mathrm{R})$ \\
\hline
\end{tabular}

The implementation of the proposed model has disclosed that F14 and F19 are the most important factors in our case study. Therefore, lubrication is the most important factor in our analysis. Table 5 shows details of grey reliability for the first class items. 
Table 3

The most important failures items

\begin{tabular}{|c|c|c|c|c|}
\hline \multirow{2}{*}{ Item } & TM1 & TM2 & TM3 & TM4 \\
\hline & $\begin{array}{lll}S & 0 & D \\
\end{array}$ & $\begin{array}{lll}S & 0 & D \\
\end{array}$ & $\begin{array}{lll}S & 0 & D \\
\end{array}$ & $\begin{array}{lll}S & 0 & D\end{array}$ \\
\hline F1 & $\begin{array}{lll}\mathrm{VH} & \mathrm{H} & \mathrm{H}\end{array}$ & $\begin{array}{lll}M & \text { VH } & \text { M }\end{array}$ & \begin{tabular}{lll|}
$\mathrm{H}$ & $\mathrm{VH}$ & $\mathrm{M}$
\end{tabular} & M $\quad$ L $\quad$ R \\
\hline F2 & $\mathrm{H} \quad \mathrm{M} \quad \mathrm{H}$ & L $\quad$ L $\quad M$ & $\mathrm{H} \quad \mathrm{M} \quad \mathrm{M}$ & M M L \\
\hline F3 & $\mathrm{M} \quad \mathrm{M} \quad \mathrm{VH}$ & L M L & M L VH & M L \\
\hline $\mathrm{F} 4$ & $\begin{array}{llll}H & M & M\end{array}$ & $\mathrm{H} \quad \mathrm{L} \quad \mathrm{R}$ & $\mathrm{L} \quad \mathrm{M} \quad \mathrm{M}$ & $\mathrm{M}$ \\
\hline F5 & VH $\quad \mathrm{M} \quad \mathrm{L}$ & M M L & M M L & M \\
\hline F6 & $\mathrm{M} \mathrm{M} \mathrm{H}$ & $\mathrm{H} \quad \mathrm{M} \quad \mathrm{R}$ & $\mathrm{H} \quad \mathrm{M} \quad \mathrm{M}$ & $\mathrm{L} \quad \mathrm{R}$ \\
\hline F7 & $\mathrm{H} \quad \mathrm{M} \mathrm{H}$ & VH L R & $\mathrm{H} \quad \mathrm{L} \quad \mathrm{H}$ & $\mathrm{M} \quad \mathrm{R}$ \\
\hline F8 & $\mathrm{H} \quad \mathrm{M} \quad \mathrm{VH}$ & L R M & M L L & $\mathrm{H} \quad \mathrm{L}$ \\
\hline F9 & L L L & $\mathrm{R} \quad \mathrm{R} \quad \mathrm{R}$ & L $\quad$ L L & $\mathrm{L} \quad \mathrm{M}$ \\
\hline F10 & $\begin{array}{lll}L & \mathrm{~L} & \mathrm{~L}\end{array}$ & $\mathrm{R} \quad \mathrm{L} \quad \mathrm{L}$ & $\mathrm{L} \quad \mathrm{H}$ & $\mathrm{R} \quad \mathrm{L}$ \\
\hline F11 & $\begin{array}{lll}\mathrm{VH} & \mathrm{H} & \mathrm{H}\end{array}$ & L M H & $\begin{array}{lll}\mathrm{L} & \mathrm{H} & \mathrm{M}\end{array}$ & M M \\
\hline F12 & $\mathrm{H} \quad \mathrm{M} \quad \mathrm{M}$ & $\mathrm{H} \quad \mathrm{L} \quad \mathrm{H}$ & $M \quad M \quad M$ & $\mathrm{H} \quad \mathrm{M}$ \\
\hline F13 & H M M & $\mathrm{L} \quad \mathrm{M} \quad \mathrm{L}$ & $\begin{array}{lll}\mathrm{L} & \mathrm{L} & \mathrm{H}\end{array}$ & M M \\
\hline F14 & H L L & $\mathrm{H} \quad \mathrm{L}$ & M L $\quad$ M & M L \\
\hline F15 & L $\quad$ L $\quad$ L & $\begin{array}{lll}\mathrm{R} & \mathrm{L} & \mathrm{R}\end{array}$ & M L $\quad$ M & L $\quad M$ \\
\hline F16 & $\mathrm{M} \quad \mathrm{H} \quad \mathrm{L}$ & $\begin{array}{lll}\mathrm{H} & \mathrm{R} & \mathrm{H}\end{array}$ & M L $\quad M$ & L $\quad$ L $\quad$ R \\
\hline F17 & $\begin{array}{lll}\mathrm{H} & \mathrm{H}\end{array}$ & $\begin{array}{lll}M & \mathrm{H} & \mathrm{VH}\end{array}$ & M VH L & M L \\
\hline F18 & M M L & $\begin{array}{lll}\mathrm{R} & \mathrm{L} & \mathrm{R}\end{array}$ & $\mathrm{L} \quad \mathrm{M} \quad \mathrm{R}$ & $\mathrm{R} \quad \mathrm{R}$ \\
\hline F19 & H $\quad$ L $\quad$ L & $\begin{array}{lll} & & \\
\end{array}$ & M L $\quad$ M & M L \\
\hline
\end{tabular}

\section{Table 4}

The summary of grey matrix

\begin{tabular}{|c|c|c|c|}
\hline Item & $\mathrm{S}$ & $\mathrm{O}$ & $\mathrm{D}$ \\
\hline $\mathrm{F}_{1}$ & {$\left[\begin{array}{ll}5 & 8.25\end{array}\right]$} & {$\left[\begin{array}{ll}5.75 & 8.25\end{array}\right]$} & {$\left[\begin{array}{ll}3 & 6.25\end{array}\right]$} \\
\hline $\mathrm{F}_{2}$ & {$\left[\begin{array}{ll}4 & 7.25\end{array}\right]$} & {$\left[\begin{array}{ll}2.5 & 6.25\end{array}\right]$} & {$\left[\begin{array}{ll}3.25 & 6.75\end{array}\right]$} \\
\hline $\mathrm{F}_{3}$ & {$\left[\begin{array}{ll}2.5 & 6.25\end{array}\right]$} & 5.5] & {$\left[\begin{array}{ll}4.5 & 7\end{array}\right]$} \\
\hline $\mathrm{F}_{4}$ & {$\left[\begin{array}{ll}4 & 7.25\end{array}\right]$} & {$\left[\begin{array}{ll}2 & 5.5\end{array}\right]$} & {$\left[\begin{array}{ll}1.5 & 4.5\end{array}\right]$} \\
\hline $\mathrm{F}_{5}$ & {$\left[\begin{array}{ll}4.25 & 7.75\end{array}\right]$} & {$\left[\begin{array}{ll}2.5 & 6.25\end{array}\right]$} & {$\left[\begin{array}{ll}0.75 & 3.5\end{array}\right]$} \\
\hline $\mathrm{F}_{6}$ & {$\left[\begin{array}{ll}4 & 7.25\end{array}\right]$} & {$\left[\begin{array}{ll}2.25 & 5.75\end{array}\right]$} & {$\left[\begin{array}{ll}2.25 & 5\end{array}\right]$} \\
\hline $\mathrm{F}_{7}$ & {$\left[\begin{array}{ll}5.75 & 8.75\end{array}\right]$} & {$\left[\begin{array}{ll}1.25 & 4.25\end{array}\right]$} & [3 5.5$]$ \\
\hline $\mathrm{F}_{8}$ & {$\left[\begin{array}{ll}4 & 7.25\end{array}\right]$} & {$\left[\begin{array}{ll}1.25 & 4.25\end{array}\right]$} & {$\left[\begin{array}{ll}3.25 & 6.25\end{array}\right]$} \\
\hline $\mathrm{F}_{9}$ & {$\left[\begin{array}{ll}0.75 & 3.5\end{array}\right]$} & {$\left[\begin{array}{ll}1.25 & 4.25\end{array}\right]$} & {$\left[\begin{array}{ll}0.5 & 3\end{array}\right]$} \\
\hline $\mathrm{F}_{10}$ & {$[0.75$ 3 $]$} & {$\left[\begin{array}{ll}2.25 & 5.25\end{array}\right]$} & {$\left[\begin{array}{ll}1 & 4\end{array}\right]$} \\
\hline $\mathrm{F}_{11}$ & {$\left[\begin{array}{ll}3.25 & 6.25\end{array}\right]$} & {$\left[\begin{array}{ll}4.5 & 8\end{array}\right]$} & {$\left[\begin{array}{ll}4 & 7.25\end{array}\right]$} \\
\hline $\mathrm{F}_{12}$ & {$\left[\begin{array}{ll}5.25 & 8.5\end{array}\right]$} & {$\left[\begin{array}{ll}3.5 & 6.25\end{array}\right]$} & {$\left[\begin{array}{ll}3.75 & 7.5\end{array}\right]$} \\
\hline $\mathrm{F}_{13}$ & {$\left[\begin{array}{ll}2.75 & 6\end{array}\right]$} & {$\left[\begin{array}{ll}3.5 & 6.25\end{array}\right]$} & {$\left[\begin{array}{ll}2.75 & 6\end{array}\right]$} \\
\hline $\mathrm{F}_{14}$ & {$\left[\begin{array}{ll}4.5 & 8\end{array}\right]$} & {$\left[\begin{array}{ll}1 & 4\end{array}\right]$} & {$\left[\begin{array}{ll}1.5 & 4.75\end{array}\right]$} \\
\hline $\mathrm{F}_{15}$ & {$\left[\begin{array}{ll}1.25 & 4.25\end{array}\right]$} & {$\left[\begin{array}{ll}1.5 & 4.75\end{array}\right]$} & {$\left[\begin{array}{ll}1.25 & 4.25\end{array}\right]$} \\
\hline $\mathrm{F}_{16}$ & {$\left[\begin{array}{ll}3.25 & 6.75\end{array}\right]$} & {$\left[\begin{array}{ll}2 & 4.75\end{array}\right]$} & {$[2.5$} \\
\hline $\mathrm{F}_{17}$ & {$\left[\begin{array}{ll}3.75 & 7.5\end{array}\right]$} & {$\left[\begin{array}{ll}5.75 & 8.75\end{array}\right]$} & {$[3.25$} \\
\hline $\mathrm{F}_{18}$ & {$\left[\begin{array}{ll}1 & 3.75\end{array}\right]$} & {$\left[\begin{array}{ll}2.75 & 5\end{array}\right]$} & {$\left[\begin{array}{ll}0.25 & 2.5\end{array}\right]$} \\
\hline$F_{19}$ & {$\left[\begin{array}{ll}4.5 & 8\end{array}\right]$} & {$\left[\begin{array}{ll}1.25 & 4.25\end{array}\right]$} & {$\left[\begin{array}{ll}1.5 & 4.75\end{array}\right]$} \\
\hline
\end{tabular}

Table 5

The summary of grey reliability for the first class items

\begin{tabular}{ccc}
\hline $\mathrm{p}$ & GRG14 & GRG19 \\
\hline 0.1 & 0.77229 & 0.93037 \\
0.2 & 0.791615 & 0.93122 \\
0.3 & 0.807915 & 0.93193 \\
0.4 & 0.82185 & 0.93252 \\
0.5 & 0.833899 & 0.93303 \\
0.6 & 0.844421 & 0.93346 \\
0.7 & 0.853689 & 0.93384 \\
0.8 & 0.861915 & 0.93417 \\
0.9 & 0.869265 & 0.93446 \\
\hline
\end{tabular}




\section{Discussion and conclusion}

In this paper, we have presented a hybrid method for detecting the most important failure items as well as the most effective alternative strategy to cope with possible events. The proposed model of this paper used grey technique to rank various alternatives and FMEA technique to find important faults. The implementation of the proposed method has been illustrated for an existing example on the literature. The results of this method have shown that the proposed model has been capable of detecting the most trouble making problems with fuzzy logic and finds the most important solution strategy using FMEA technique.

\section{References}

Bai, C., \& Sarkis, J. (2011). Evaluating supplier development programs with a grey based rough set methodology. Expert Systems with Applications, 38(11), 13505-13517.

Bevilacqua, M., Braglia, M., \& Gabbrielli, R. (2000). Monte Carlo simulation approach for a modified FMECA in a power plant. Quality and Reliability Engineering International, 16(4), 313324.

Bowles, J. B., \& Peláez, C. E. (1995). Fuzzy logic prioritization of failures in a system failure mode, effects and criticality analysis. Reliability Engineering \& System Safety, 50(2), 203-213.

Braglia, M. (2000). MAFMA: multi-attribute failure mode analysis. International Journal of Quality \& Reliability Management, 17(9), 1017-1033.

Braglia, M., Frosolini, M., \& Montanari, R. (2003). Fuzzy TOPSIS approach for failure mode, effects and criticality analysis. Quality and Reliability Engineering International, 19(5), 425-443.

Chang, C. L., Wei, C. C., \& Lee, Y. H. (1999). Failure mode and effects analysis using fuzzy method and grey theory. Kybernetes, 28(9), 1072-1080.

Hawkins, P.G., \& Woollons, D. J. (1998). Failure modes and effects analysis of complex engineering systems using functional models. Artificial Intelligence in Engineering, 12(4), 375-397.

Hwang, C. L., \& Yoon, K. (1981). Multiple attribute decision making. Berlin: Springer.

James, E. B. (1998). Risk analysis: Two tools you can use to assure product safety and reliability.

Li, G. D., Yamaguchi, D., \& Nagai, M. (2008). A grey-based rough decision-making approach to supplier selection. The International Journal of Advanced Manufacturing Technology, 36(9-10), 1032-1040.

Puente, J., Pino, R., Priore, P., \& de la Fuente, D. (2002). A decision support system for applying failure mode and effects analysis. International Journal of Quality \& Reliability Management, 19(2), 137-150.

Rhee, S. J., \& Ishii, K. (2003). Using cost based FMEA to enhance reliability and serviceability. Advanced Engineering Informatics, 17(3), 179-188.

Sankar, N. R., \& Prabhu, B. S. (2001). Modified approach for prioritization of failures in a system failure mode and effects analysis. International Journal of Quality \& Reliability Management, 18(3), 324-336.

Scipioni, A., \& Andreazza, D. (1997). Il sistema HACCP. Sicurezza e qualità nelle aziende agroalimentari. Hoepli Editore.

Wang, J., Ruxton, T., \& Labrie, C. R. (1995). Design for safety of engineering systems with multiple failure state variables. Reliability Engineering \& System Safety, 50(3), 271-284.

Wang, Y. M., Chin, K. S., Poon, G. K. K., \& Yang, J. B. (2009). Risk evaluation in failure mode and effects analysis using fuzzy weighted geometric mean. Expert Systems with Applications, 36(2), 1195-1207.

Yang, Z., Xu, B., Chen, F., Hao, Q., Zhu, X., \& Jia, Y. (2010). A new failure mode and effects analysis model of CNC machine tool using fuzzy theory. In Information and Automation (ICIA), 2010 IEEE International Conference on (pp. 582-587). IEEE. 